\title{
Data Analysis and Presentation using Statistical Techniques
}

\author{
Neville Greening \\ Doctor of Philosophy Academic Mixed Research Methods \\ Osaka University-8-1-1 Aomatani-Higashi, Minoh, \\ OSAKA 562-8558 JAPAN \\ Email: Osaka.university2017@gmail.com \\ DOI: 10.31364/SCIRJ/v7.i9.2019.P0919692 \\ http://dx.doi.org/10.31364/SCIRJ/v7.i9.2019.P0919692
}

\begin{abstract}
This assignment deals with two primary case studies - one dealing with the estimation of several golfers in the U.S.A, and those who rank top in earnings, and the second case study will focus on the hypothesis test for the mean and standard deviation of the temperature of hot chocolates. The data for golfers were collected through observational research, whereas the research data for temperature is collected through experimental research. In this research, both descriptive and inferential statistics are used for the analyses. In both case studies, we have used Minitab as an analytical tool.
\end{abstract}

Keywords: hypothesis test, standard deviation, descriptive and inferential statistics, Minitab

Introduction

Case 1: This mini-case assignment aims to estimate the number of golfers in American from the age of eighteen and above and to estimate the amount of golfers who earn over $\$ 75,000$.

Case 2: This assignment aims to verify whether the temperature of hot chocolate at D's Bagels owned by David is maintained at the desired temperature within the desired standard deviation

The two mini-case assignments are successfully analyzed using statistical techniques.

\section{Mini-case assignment-1}

This mini-case assignment aims to estimate the number of golfers in American from the age of eighteen and above and to estimate the number of golfers who earn over $\$ 75,000$. The data was collected through a survey of 1,116 U.S adults of age 18 and above. The responses were recorded as the categories of household income and whether the subject had played golf at least once during summer. The variable household income is structured as an ordinal variable, and the variable golfer is structured as a dichotomous variable. The appropriate graphical methods and descriptive methods to display the above use two variables, as mentioned below. Descriptive analysis refers to the transformation of raw data into a form that will make it easy to understand and interpret (ZIKMUND, William 
G., 2003). The most appropriate descriptive method to display categorical data is the cross-tabulation. The following cross-tabulations present the data of golfers categorized by income.

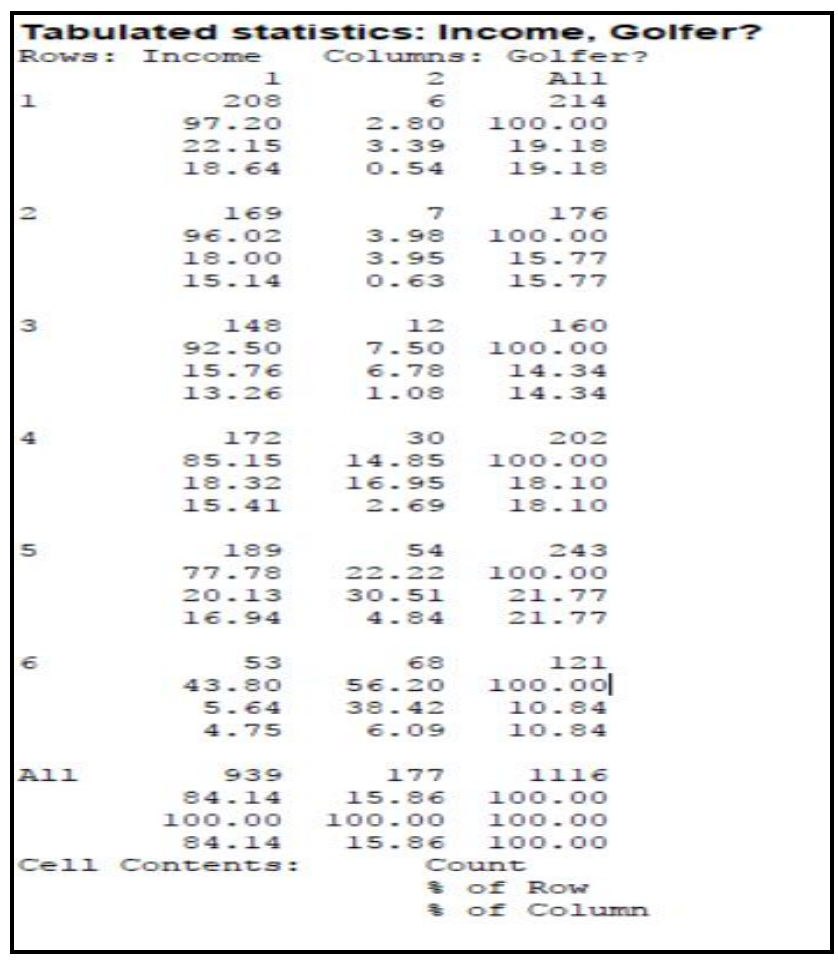

Figure 1: Cross-tabulation - Income and Golfer

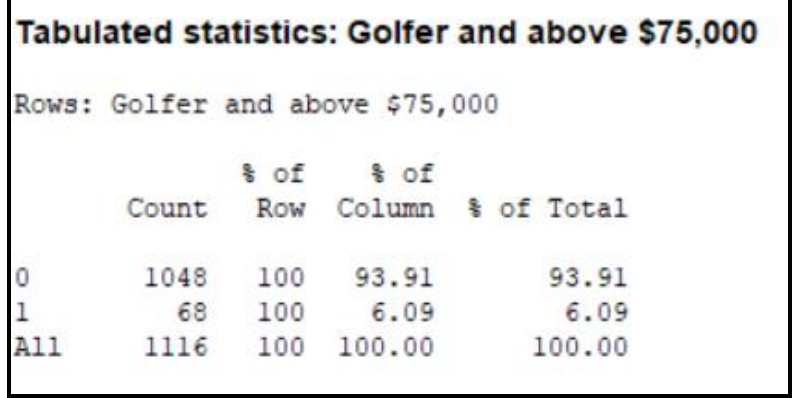

Figure 2: Tabulation - Golfer earning over $\$ \mathbf{7 5 , 0 0 0}$

The appropriate graph to display the categorical data is the bar graph. The following bar graphs show the distribution of golfers and non-golfers across the income categories. 


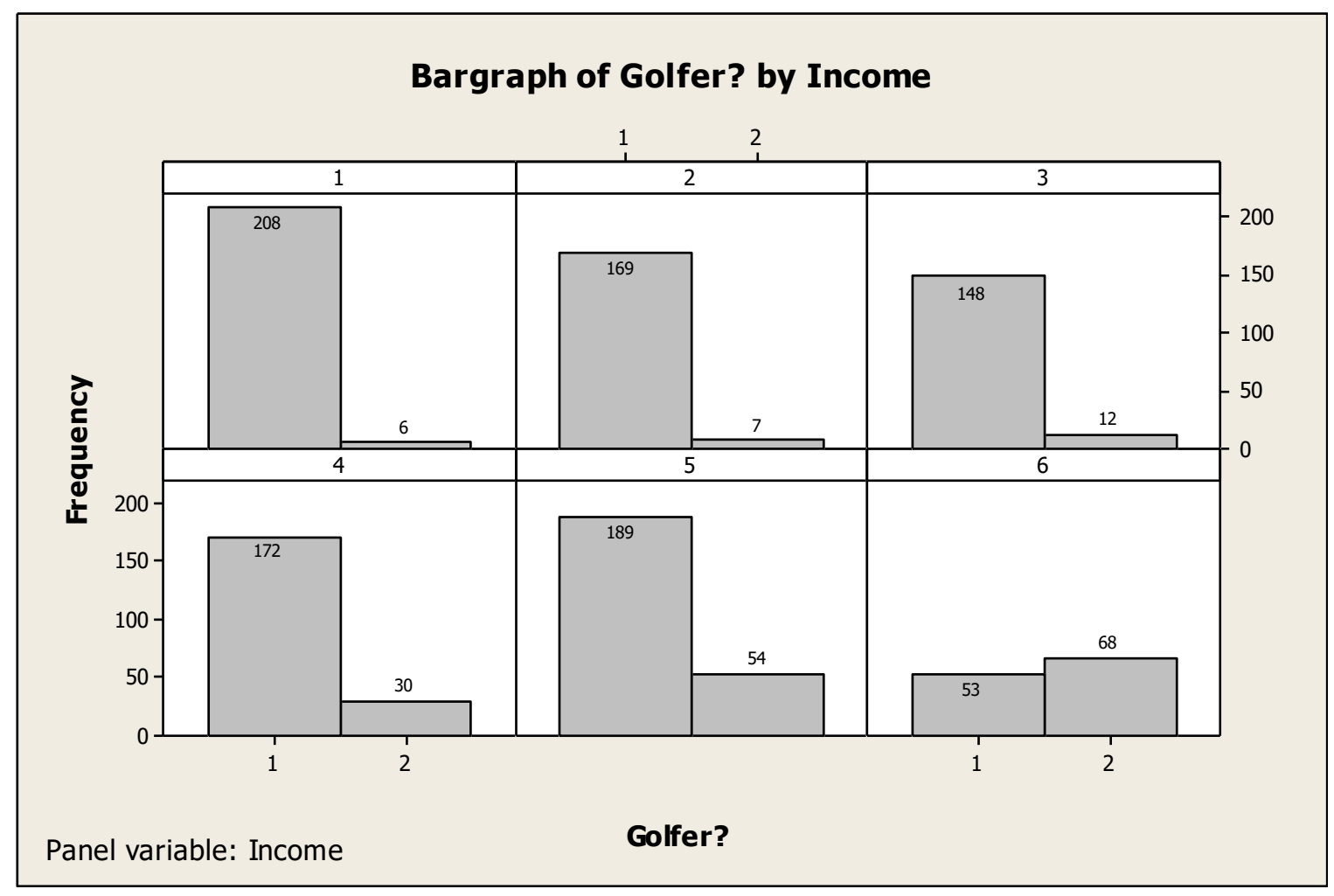

Figure 3: Bar graphs number of non-golfers and golfers by income

In the above graph, the difference in the number of golfers and non-golfers is negligible in the $6^{\text {th }}$ income category, which is over $\$ 75,000$. The most appropriate measure of central tendency for the income data is mode as it is the only valid measure of central tendency for categorical data.

The following is the Minitab output of descriptive statistics of income categorized by golfers.

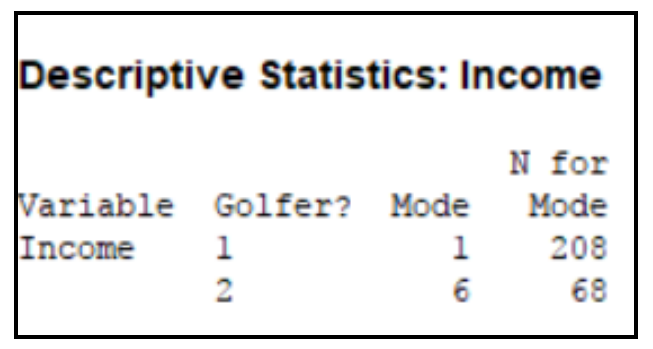

Figure 4: Descriptive statistic of income by Golfers

The above table shows that most non-golfers are of income level under $\$ 35,000$, and the majority of golfers are of income level over $\$ 75,000$. This measure somewhat leads to a rough approximation that golf is the rich men's game. 
From the cross-tabulation, it is evident that 177 of the 1,116 persons are golfers. Estimating the total number of golfers is equivalent to calculating the population proportion of golfers from the sample proportion. Evaluating with $95 \%$ confidence is framing the $95 \%$ confidence interval. The $95 \%$ confidence interval for population proportion $p$ is represented as follows using the standard normal distribution as the sampling distribution.

$$
p \pm z_{0.025} \sqrt{\frac{p(1-p)}{n}}(\text { VOELKER, David H., and Orton, Peter Z., 2001) }
$$

Here $p$ is the sample proportion, $\mathrm{z}_{0.025}$ is the two-sided critical value of standard normal distribution at $95 \%$ confidence level, and $n$ is the sample size. Their following conditions need to be satisfied for estimating proportions.

$$
\begin{aligned}
n p & \geq 10 \\
n(1-p) & \geq 10
\end{aligned} \text { (VOELKER, David H., and Orton, Peter Z., 2001) }
$$

Substitute $n=1,116$ and $p=0.16$ in the above conditions.

$$
\begin{aligned}
1,116(0.16) & \approx 179>10 \\
1,116(1-0.16) & \approx 937>10
\end{aligned}
$$

The conditions are satisfied. The following Minitab output provides a 95\% confidence interval for the proportion of golfers.

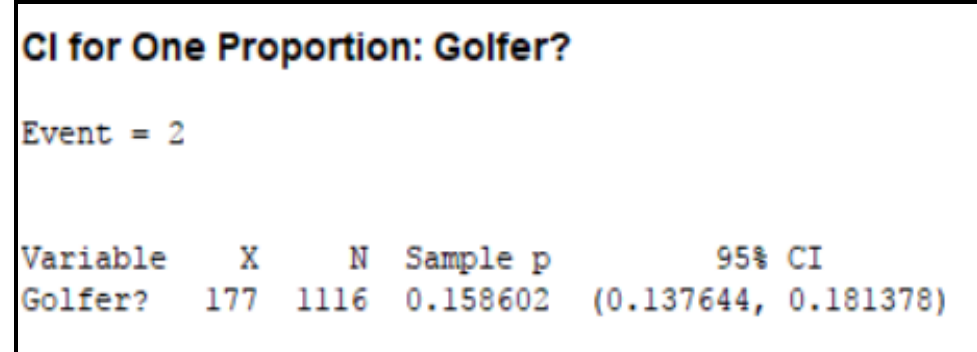

Figure 5: 95\% Confidence interval for the percentage of golfers

From the above Minitab output, the $95 \%$ confidence interval for the population proportion of golfers in the U.S is (0.14, 0.18). With $95 \%$ confidence, it can be estimated that the percentage of golfers in the U.S is between $14 \%$ and $18 \%$.

From the cross-tabulation, it is evident that 68 of the 1,116 persons are golfers earning over $\$ 75,000$. Estimating the total number of golfers making over $\$ 75,000$ is equivalent to determining the population proportion of golfers earning over $\$ 75,000$ from the sample proportion. Calculating with $95 \%$ confidence is comparable to framing the $95 \%$ confidence interval. The $95 \%$ confidence interval for population proportion $p$ is represented as follows using the standard normal distribution as the sampling distribution. 


$$
p \pm z_{0.025} \sqrt{\frac{p(1-p)}{n}}(\text { VOELKER, David H., and Orton, Peter Z., 2001) }
$$

Here $p$ is the sample proportion, $\mathrm{z}_{0.025}$ is the two-sided critical value of standard normal distribution at $95 \%$ confidence level, and $n$ is the sample size. Their following conditions need to be satisfied for estimating proportions.

$$
\begin{aligned}
n p & \geq 10 \\
n(1-p) & \geq 10
\end{aligned} \text { (VOELKER, David H., and Orton, Peter Z., 2001) }
$$

Substitute $n=1,116$ and $p=0.06$ in the above conditions.

$$
\begin{aligned}
1,116(0.06) & \approx 67>10 \\
1,116(1-0.06) & \approx 1,045>10
\end{aligned}
$$

The conditions are satisfied. The following Minitab output provides the $95 \%$ confidence interval for the proportion of golfers earning over $\$ 75,000$.

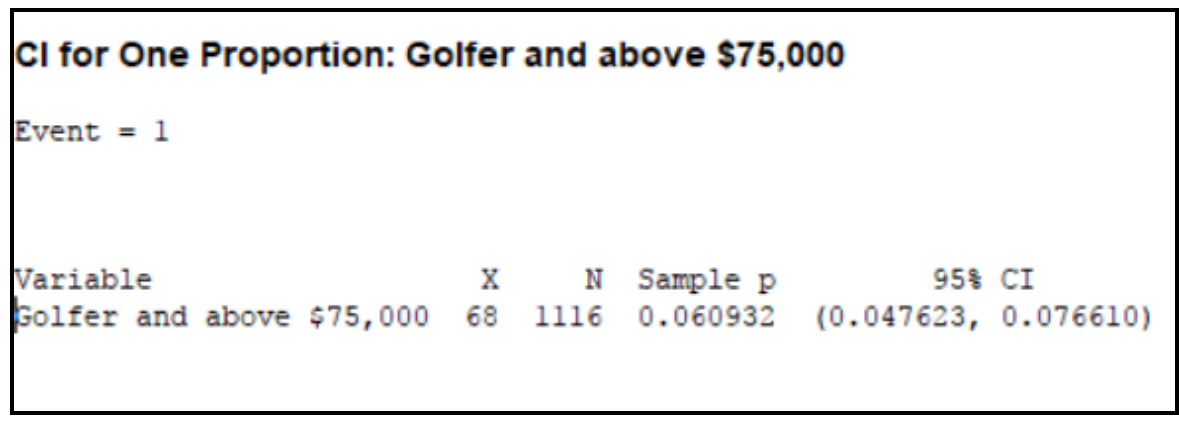

Figure 6: $95 \%$ Confidence interval for golfers earning over $\$ \mathbf{\$ 5 , 0 0 0}$

From the above Minitab output, the $95 \%$ confidence interval for the population proportion of golfers in the U.S earning over $\$ 75,000$ is $(0.05,0.08)$. With $95 \%$ confidence, it can be estimated that the portion of golfers in the U.S making $\$ 75,000$ is between $5 \%$ and $8 \%$.

$$
\text { Mini case assignment }-2
$$

This assignment aims to verify whether the temperature of hot chocolate at D's Bagels owned by David is maintained at the desired temperature within the desired standard deviation. The data of temperature were collected randomly by David for 25 cups of hot 
chocolate. As the variable temperature is of an interval scale, the appropriate measures of central tendency are mean, median and mode and means of spread are interpretable (WALLER, Derek L., 2008).

The following Minitab output gives the descriptive measures of temperatures of 25 hot chocolate samples.

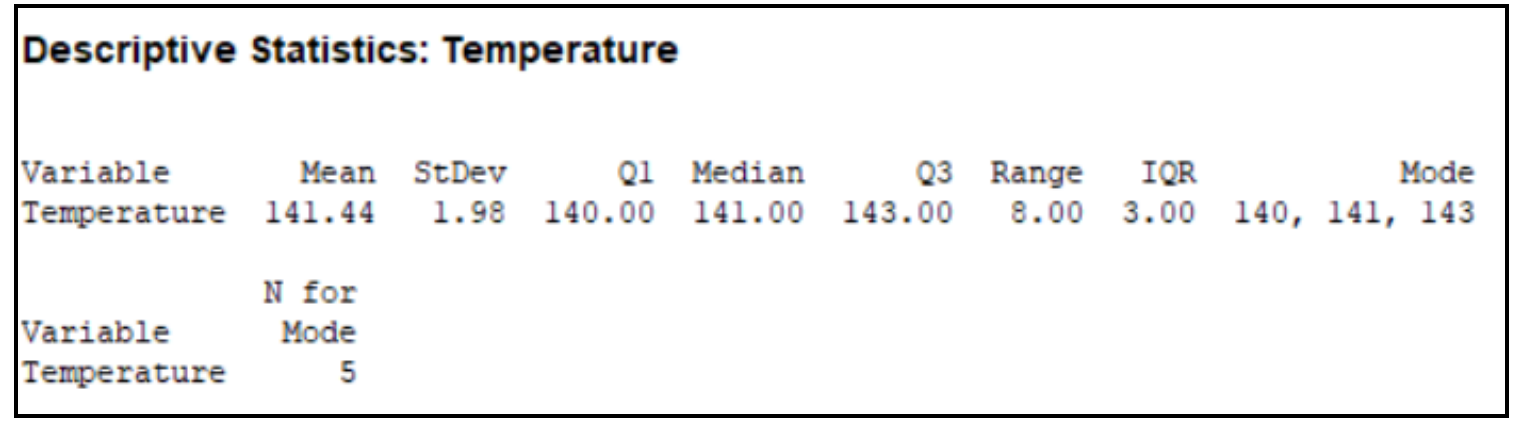

Figure 7: Descriptive statistics - Temperature

Using the Minitab output, it is clear that the sample mean temperature is 141.44 degrees Celsius, the sample median temperature is 143 degrees Celsius, and the mode temperatures are 140, 141, and 143. The sample standard deviation of the heat is 1.98 .

The appropriate graphs to display the temperature are histogram and boxplot (R.S.N, Pillai, and V., Bagavathi, 2003). The histogram and boxplot of temperature are as follows.

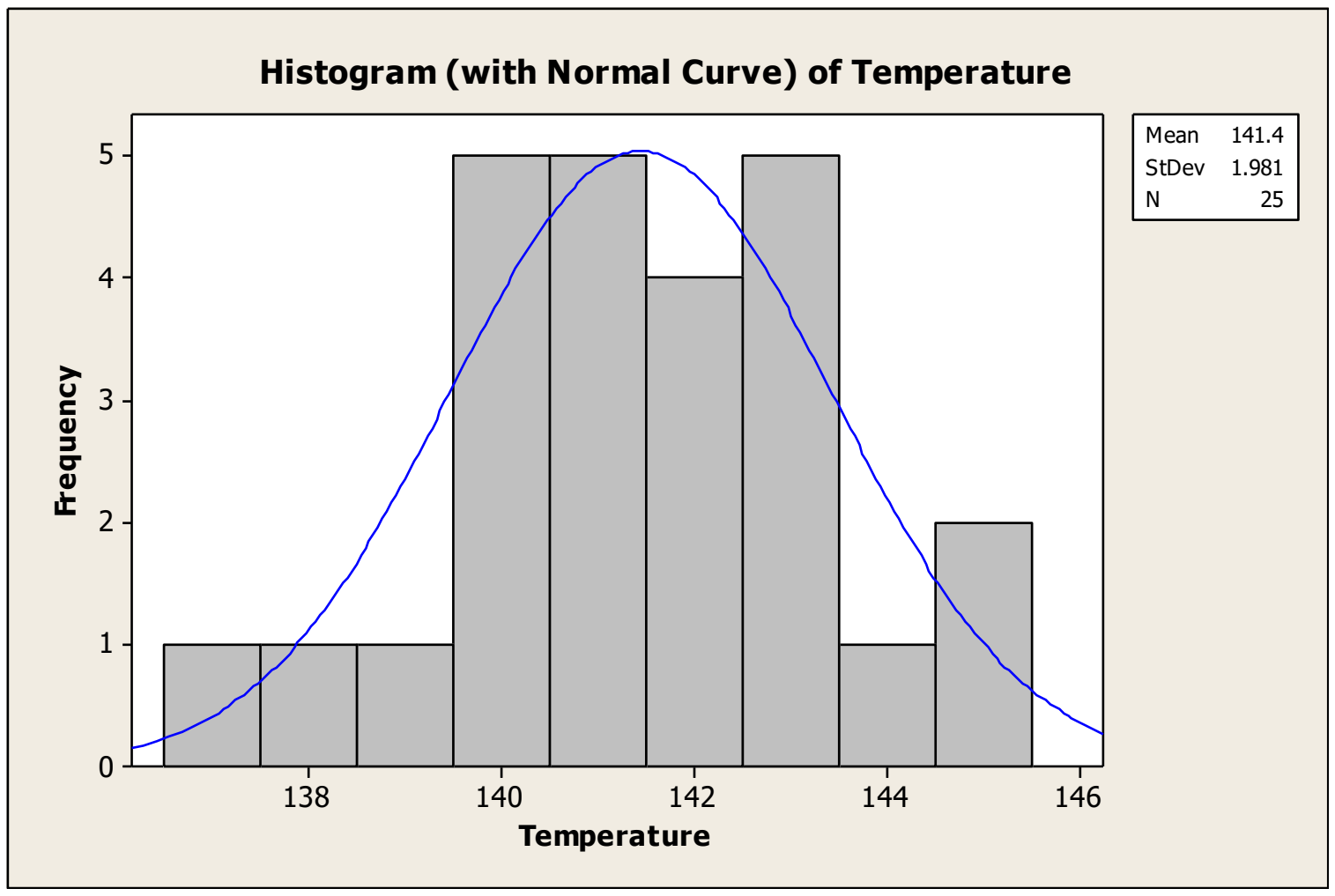

Figure 8: Histogram of temperatures

www.scirj.org

(C) 2019, Scientific Research Journal

http://dx.doi.org/10.31364/SCIRJ/v7.i8.2019.P0819XX 


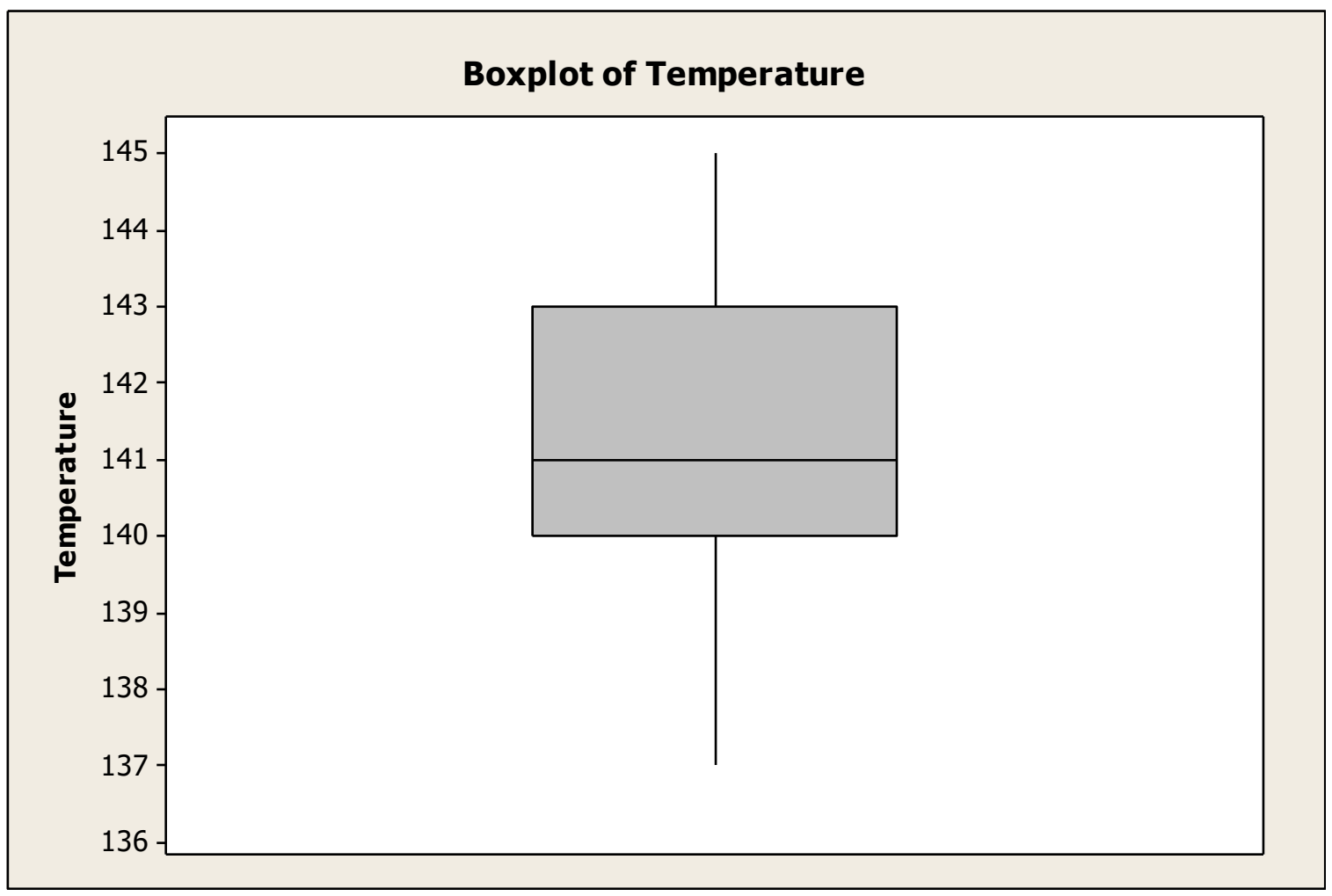

Figure 9: Boxplot of temperatures

The above histogram and boxplot of temperature show that the distribution of temperature is approximately normal, and no outliers are present. To test whether the sample provided sufficient evidence for desired mean temperature and standard deviation of temperature, our hypothesis test offers us the relevant data.

Research hypothesis: Is the sample data evidence to show that the actual mean temperature of the hot chocolate differs from 142 degrees at $10 \%$ significance?

Null hypothesis $H_{0}$ : The correct mean temperature of the hot chocolate does not differ from 142 degrees. $(\mu \neq 142)$.

Alternate hypothesis $H_{1}$ : The exact mean temperature of the hot chocolate differs from 142 degrees. $(\mu \neq 142)$.

Appropriate test: The proper statistical analysis to verify this claim is the Student's test for the single sample mean as the sample size is less than 30 , and the population standard deviation is unknown.

\section{Assumptions:}

i) The samples should be random and independent.

ii) The samples should be drawn from the general population. (MONTGOMERY, Douglas C., 2009)

www.scirj.org

(C) 2019, Scientific Research Journal

http://dx.doi.org/10.31364/SCIRJ/v7.i8.2019.P0819XX 
The validity of assumptions:

i) As the examples are random, randomness and independence are valid.

ii) From the histogram and boxplot, the distribution of temperature is approximately normal.

Test statistic:

$$
\frac{\bar{X}-\mu}{s / \sqrt{n}} \square t_{n-1} \text { (BLUMAN, Allan G, 2009) }
$$

Minitab output:

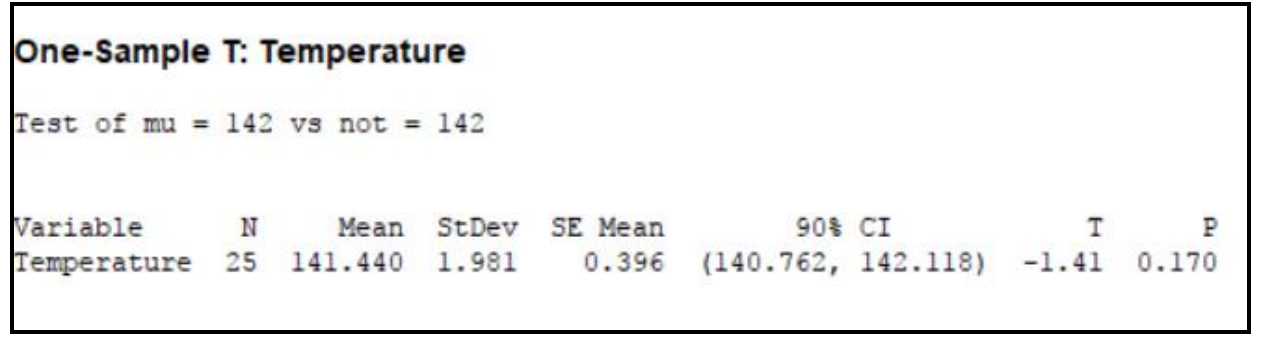

Figure 10: One sample t-test for mean temperature

Decision:

From the above Minitab output, the value of the observed t-statistic value is -1.41 with $p$-value 0.170 . As the $p$-value exceeds the level of significance, there is no evidence against the null hypothesis. It is wise to conclude that the correct mean temperature of hot chocolates does not differ from 142 degrees.

Research hypothesis: Is the sample data evidence to show that the correct standard deviation temperature of the hot chocolate is higher than 3 degrees at $10 \%$ significance?

Null hypothesis $H_{0}$ : The true mean, standard deviation temperature of the hot chocolate is less than or equal to 3 degrees. $(\sigma \leq 3)$.

Alternate hypothesis $H_{1}$ : The accurate mean, standard deviation temperature of the hot chocolate is greater than 3 degrees. $(\sigma>3)$. Appropriate test: The most logical statistical analysis to verify this claim is the Chi-square test for a single sample (WALLER, Derek L., 2008). 


\section{Assumptions:}

i) The samples should be random and independent.

ii) The samples should be drawn from a healthy population. (MONTGOMERY, Douglas C., 2009)

The validity of assumptions:

i) As the examples are random, randomness and independence are valid.

ii) From the histogram and boxplot, the distribution of temperature is approximately normal.

Test statistic:

$$
\sqrt{\frac{(n-1) S^{2}}{\sigma^{2}}} \square \chi_{n-1}^{2}
$$

Minitab output:

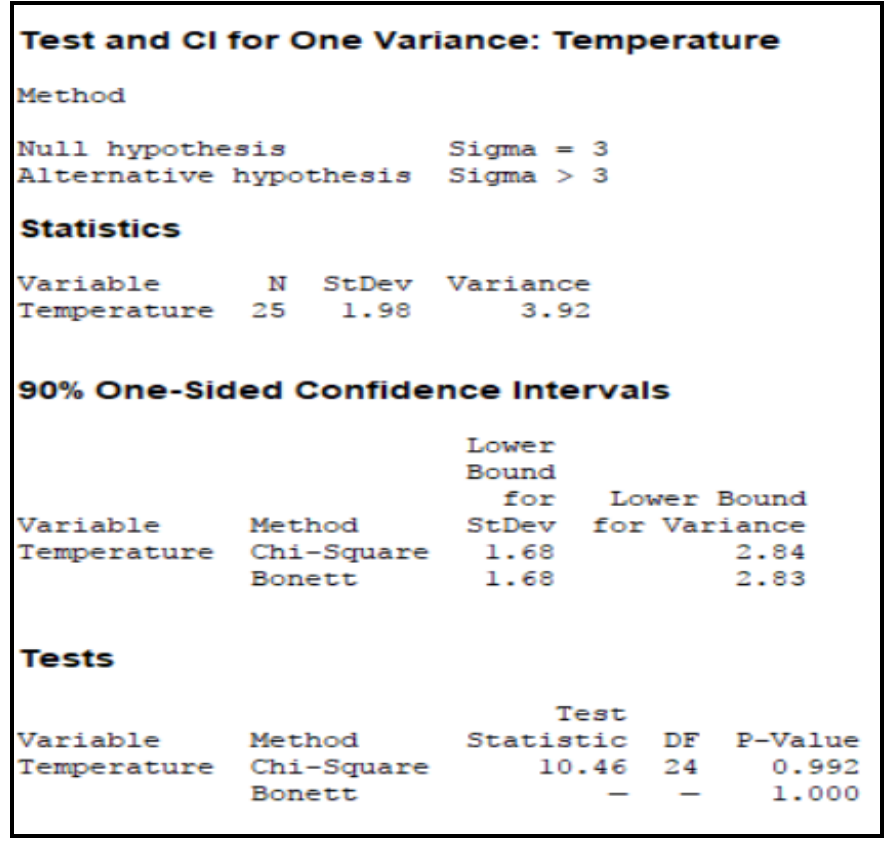

Figure 11: Chi-square test for standard deviation of temperature

Decision:

From the above Minitab output, the value of the observed chi-squared-statistic value is 10.46 with one-sided $p$-value 0.992 . As the $p$-value exceeds the level of significance, there is no evidence against the null hypothesis. It is wise to conclude that the actual mean, standard deviation temperature of the hot chocolate is less than or equal to 3 degrees.

www.scirj.org

(C) 2019, Scientific Research Journal

http://dx.doi.org/10.31364/SCIRJ/v7.i8.2019.P0819XX 


\section{Conclusion}

The two mini-case assignments are successfully analyzed using statistical techniques. The result for the first mini-case task shows that the correct proportion of the golfers in the U.S is between $14 \%$ and $18 \%$ whereas the actual percentage of the golfers in the U.S earning over $\$ 75,000$ is between $5 \%$ and $8 \%$. The result for the second mini-case assignment shows that the correct mean temperature of hot chocolates is 142 degrees, and the actual standard deviation of temperature is less than or equal to 3 degrees. These results are limited to the validity of samples and sampling techniques. It is suggested to get more data samples and compare the results for the reliability of the inferences.

\section{References}

1: BLUMAN, Allan, G., 2009. Elementary statistics A step by step approach, Seventh edition. New York: The McGraw-Hill Companies Inc.

2: MONTGOMERY, Douglas C., 2009. Statistical Quality Control A modern introduction, Sixth edition. New Delhi: Willey India Pvt Ltd.

3: R.S.N, Pillai, and Bagavathi V. 2003. Statistics. New Delhi: S.Chand \& company.

4: VOELKER, David H., and Peter Z. ORTON. 2001. Cliffs quick review of Statistics. New York: Hungry Minds, Inc.

5: WALLER, Derek L., 2008. Statistics for Business. Burlington: Elsevier, Inc.

6: ZIKMUND, William G., 2003. Business research methods, Seventh edition. Cincinnati: Thomson / South-Western. 